\title{
New Resonant Inverter Tuning for Three-Phase Current Source Parallel Resonant Inverters
}

\author{
Alireza Namadmalan ${ }^{1}$, Javad Shokrollahi Moghani ${ }^{2}$ \\ ${ }^{1}$ Jundi-Shapur University of Technology, Dezful, Iran, namadmalan@jsu.ac.ir \\ ${ }^{2}$ Amirkabir University of Technology, Tehran, Iran, moghani@aut.ac.ir
}

\begin{abstract}
This paper presents a new tuningloop for three-phase current source parallel resonant inverters. The switching frequency is tuned by using a phase-locked loop (PLL) circuit based on a new Phase Detector (PD). In practice, the resonant capacitors and inductors have tolerances that cause different resonant frequency for each phase. This paper shows that a conventional PDcauseshigher voltage stress over switches and DC-link inductor. In the proposed tuning loop, the PLL tracks the average value of the resonant frequencies that reduces the voltage stress. In addition, there is no feedback from the loadcurrents to detect the phase error, which is another advantage of the new method. A laboratory prototype of a three-phase current source parallel resonant half-bridge inverter was built to verify the advantages of the proposed tuning system with operating frequency of $22 \mathrm{kHz}$.
\end{abstract}

Keywords: resonant inverter tuning; three-phase current source parallel resonant inverters; phase-locked loop (PLL)

\section{Introduction}

Resonant Inverters are most commonly used because they provide sinusoidal waveforms with lower harmonics and less EMI problems. A large number of topologies have been developed in this area which can be divided into singlephase and multi-phase structures. Three-phase resonant inverters are widely used in industrial applications. Such applications include high power DC-DC converters, contact-less power transfer systems and multi-phase induction heating systems [1-13].

In comparison with single-phase resonant inverters, the three-phase inverters have a smaller input filter and higher power density. Moreover, the load currents and output voltages have less distortion due to third order harmonics elimination for three-wire structures. Hence, the three-phase resonant inverters have better sinusoidal waveforms in low quality factors $(Q<5)$ which is important in traveling wave induction heating systems [9]. 
Three-phase current-fed parallel resonant inverters are widely utilized in high voltage and high power DC-DC converters; because they provide higher boosting ratio and they have no current sharing problems. The current source inverters have limited control methods but they are less affected by input voltage ripples and they have short-circuited protection capability [13-20]. Figure 1 shows two possible topologies for three-phase current source parallel resonant inverters with threewire connection.

Conventionally, PDs measure the phase difference between the voltage and the current of a single resonant tank [21-25]. Hence, a conventional PLL is applicable when the three resonant tanks have a same resonant frequency. However, designing the three resonant tanks without tolerance and frequency deviation is practically impossible. This paper shows that the three-phase current source topologies are sensitive to the tolerances and the systems are unbalanced under no-load and light-load conditions. In addition, the switching losses, DC-link current ripples and voltage stress are increased. The proposed PD tracks the average value of the resonant frequencies that reduces the DC-link current ripples and voltage stress over the switches $S_{1}-S_{6}$.

In a conventional tuning loop, the current of resonant tank is measured for phase error detection. In the new PLL, voltages of the low-side switches are the inputs of the PD and there is no feedback from the output currents. Thus, there is no Current Transformer (CT) or Hall Effect sensor for current sensing, which makes the system simple, more reliable and cost effective. The dynamic behavior of the new tuning loop is simulated in steady state and transient conditions. The proposed PD has similar structure for the two topologies, as shown in Figure 1. For simplicity, the laboratory prototype is implemented based on the half-bridge inverter.

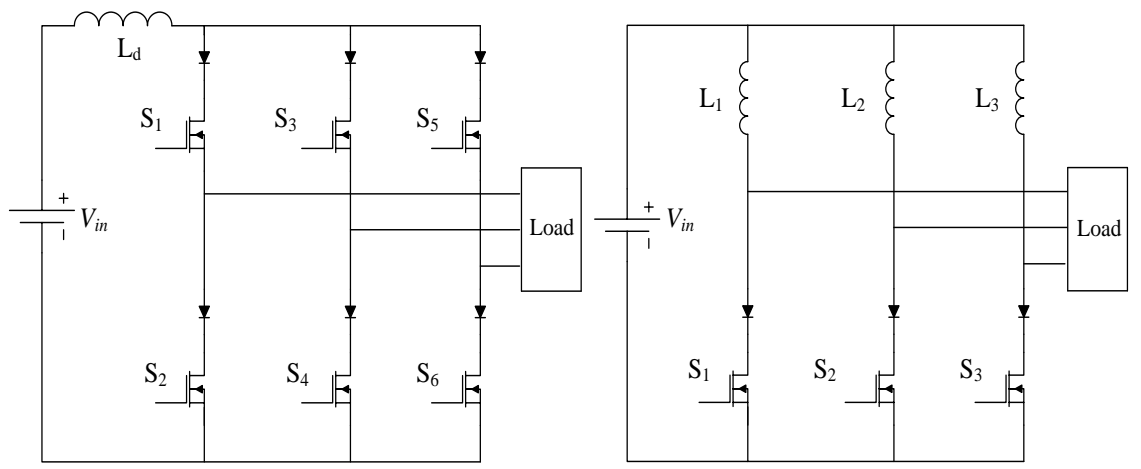

(a)

(b)

Figure 1

Three-phase current source parallel resonant topologies: (a) the full-bridge inverter; (b) the half-bridge inverter 


\section{System Description}

Figure 2 shows the half-bridge topology with a star-connected resonant tank. The performance of the resonant inverter tuning is similar for the half-bridge and fullbridge inverters. In the both cases, each switch conducts 120 degrees to achieve Zero Voltage and Zero Current Switching (ZVZCS) at the resonant frequency. The half-bridge inverter has asymmetrical current injection while the full-bridge inverter has symmetrical current injection.

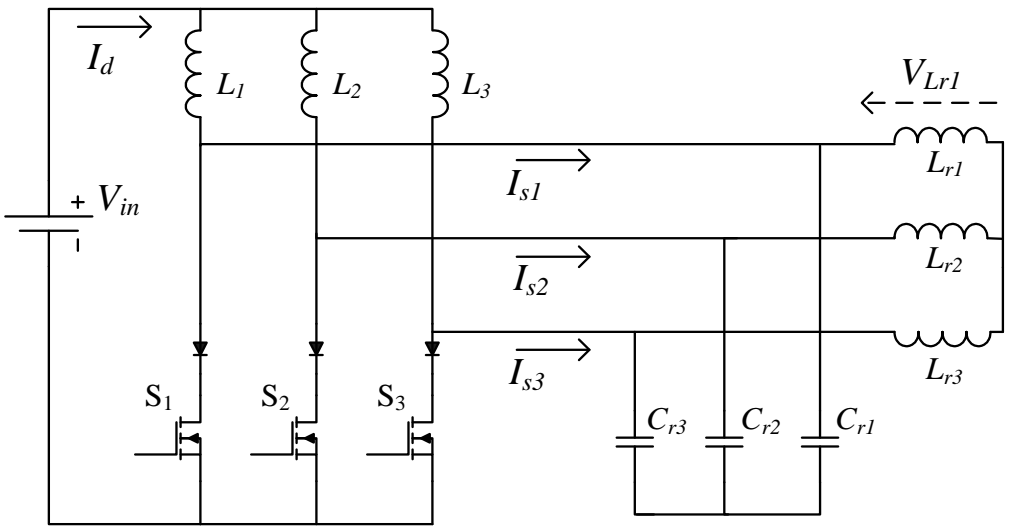

Figure 2

The half-bridge inverter with star-connected resonant tank

Figure 3 shows the three-step operation of the half-bridge inverter where each switch conducts for 120 degrees of the switching period. Each switch is connected in series with a blocking diode to prevent the internal body diode of the switches from short circuit. Operation of the inverters is investigated with and without the tolerances as follows:

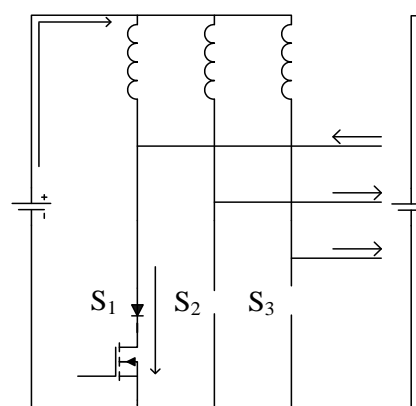

(a)

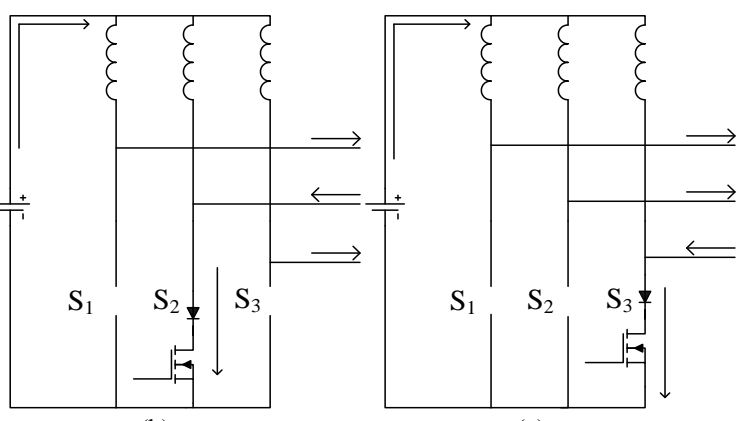

(b) (c)

Figure 3

Three-step operation of the half bridge inverter 


\subsection{Operation without the Tolerances}

In this section, the parameters of the inverter are considered with no tolerance. Hence, the three resonant tanks have a similar resonant frequency. The inductance of $L_{1}, L_{2}$ and $L_{3}$ ( $L_{d}$ for full-bridge inverter as seen from Figure 1) are much larger than the resonant inductors $\left(L_{r 1}=L_{r 2}=L_{r 3}=L_{r}\right)$, so under normal steady state operation the DC-link current, $I_{d}$, is approximately constant.

Regarding Figure 3, voltage of $S_{1}$ is derived by equation (1) for a switching period duration while the converter works at the resonant frequency. The $\omega_{r}, T_{s}, C_{r}$ and $V_{m}$ are the angular resonant frequency, switching period, per-phase resonant capacitor and phase-phase voltage of the inverter.

$$
\begin{array}{rlrl}
V_{S 1}=0, & <t<\frac{T_{s}}{3} & \\
V_{S 1}=V_{m} \sin \left(\omega_{r} t-\frac{2 \pi}{3}\right), & \frac{T_{s}}{3}<t<\frac{2 T_{s}}{3} \quad, \omega_{r}=2 \pi f_{r}=\frac{1}{\sqrt{L_{r} C_{r}}} \\
V_{S 1}=-V_{m} \sin \left(\omega_{r} t\right), & \frac{2 T_{s}}{3}<t<T_{s} &
\end{array}
$$

For the half-bridge inverters, the amplitude of the phase-phase voltage, $V_{m}$, is derived by employing the inductor volt-second balance principle on $L_{l}$, where $V_{\text {in }}$ is the DC-link voltage. Similarly, $V_{m}$ is derived by equation (3) for the full-bridge inverters by employing the inductor volt-second balance principle on $L_{d}$.

$$
\begin{aligned}
& \int_{0}^{2 \pi} V_{L 1} d \theta=\int_{0}^{\frac{2 \pi}{3}} V_{i n} d \theta+\int_{\frac{2 \pi}{3}}^{\frac{4 \pi}{3}}\left[V_{i n}-V_{m} \sin \left(\theta-\frac{2 \pi}{3}\right)\right] d \theta+\int_{\frac{4 \pi}{3}}^{2 \pi}\left[V_{i n}+V_{m} \sin (\theta)\right] d \theta=0 \\
& \rightarrow V_{m}=\frac{2 \pi}{3} V_{i n} \\
& V_{m}=\frac{\pi}{3} V_{i n}
\end{aligned}
$$

Figure 4 shows per-phase equivalent circuit of the resonant inverter and $R$ is the per-phase load resistance. According to $120^{\circ}$ conduction, the $I_{s l}$ and voltage of $S_{1}$ are shown in Figure 5 for the full-bridge and half bridge topologies at the resonant frequency. For the both topologies, the peak voltage of the switches is the amplitude of the phase-phase voltage or $V_{m}$. The DC-link voltage, $V_{i n}$, of the two topologies is $50 \mathrm{~V}$. As seen from Figure 5(b), the injected current of the fullbridge inverter has no third order harmonics. Hence, the inverter have lower THD of current for low quality factor operations $(Q<5)$, in comparison with singlephase topologies [14-20].

The quality factor of the parallel resonant load is derived by equation (4). For the half-bridge topology, the injected current has second order harmonics and is suitable for high quality factor operations. In addition, the half-bridge topology is useful for high boosting ratio converters, as shown in equation (2). 
$Q=\frac{R}{\omega_{r} L_{r}}$

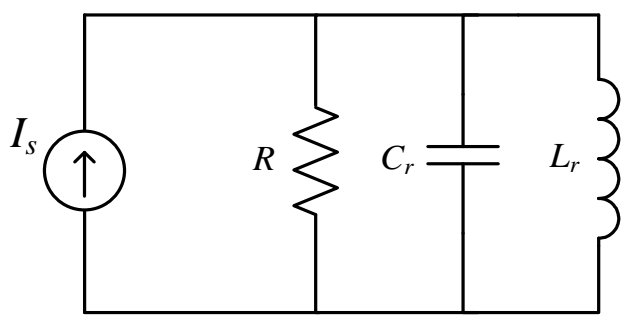

Figure 4

Single-phase equivalent circuit of the resonant tank and the inverter

Let's consider that the switching frequency of the inverter is greater (or smaller) than the resonant frequency. Hence, there is a phase difference, $\beta$, between the injected current, $I_{s}$, and voltage of the tank circuit. Figure 6 shows the phase plot of a parallel resonant tank with quality factor of 10 and resonant frequency of 25 $\mathrm{kHz}$. The phase plot represents the phase difference $\beta$ between the injected current $I_{s}$ and the resonant tank voltage for different switching frequencies.

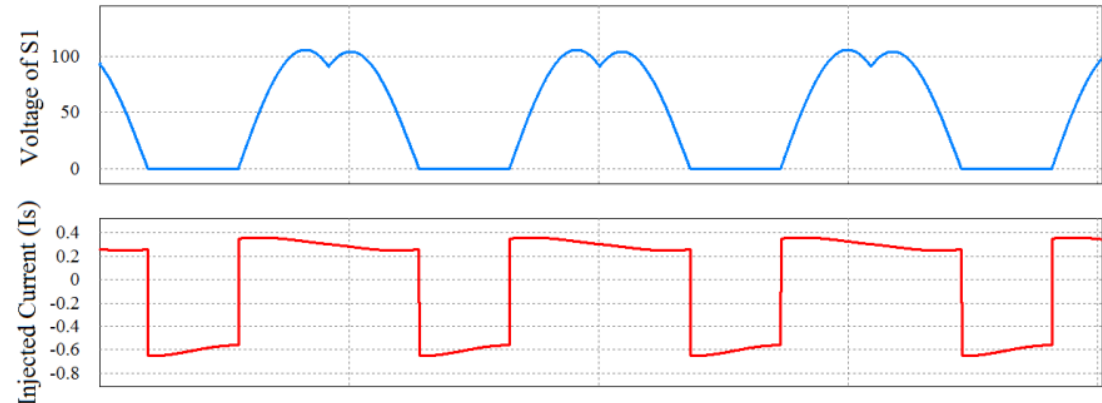

(a)

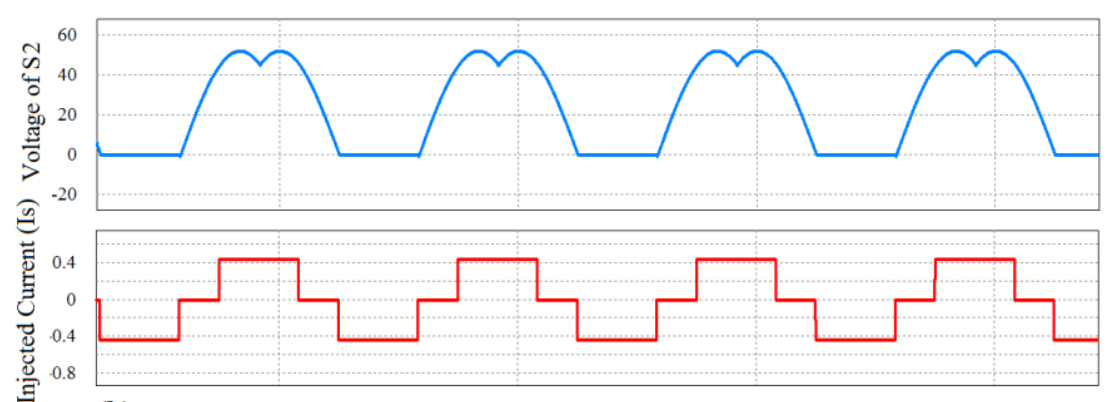

(b)

Figure 5

The voltage of $S_{1}$ and the injected current connected to $S_{1}, I_{s I}$ : (a) for the half-bridge inverter;

(b) voltage for the full-bridge inverter 


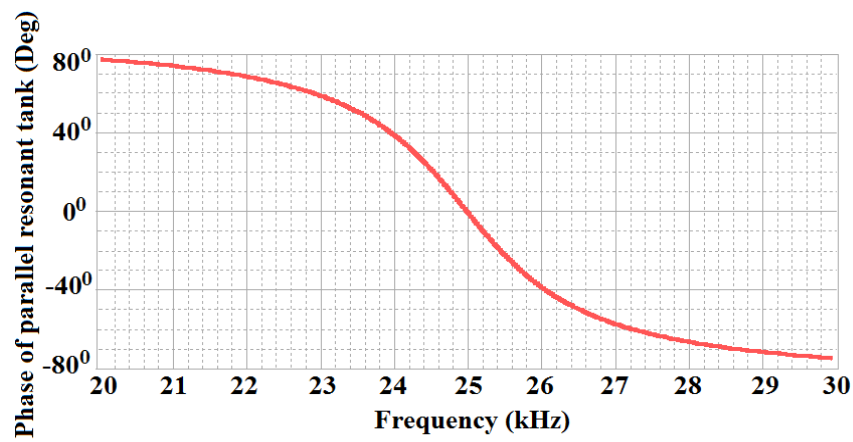

Figure 6

Phase plot of a parallel resonant tank with quality factor of 10

Figure 7 shows the voltage of $S_{1}$ and the phase difference $\beta$ for two conditions (over and under the resonant frequency). Regarding equation (2), the peak value of the phase-phase voltage, $V_{m}$, is rewritten as follows:

$$
\begin{aligned}
& \int_{0}^{2 \pi} V_{L 1} d \theta=\int_{0}^{\frac{2 \pi}{3}} V_{i n} d \theta+\int_{\frac{2 \pi}{3}}^{\frac{4 \pi}{3}}\left[V_{i n}-V_{m} \sin \left(\theta-\frac{2 \pi}{3}+\beta\right)\right] d \theta+\int_{\frac{4 \pi}{3}}^{2 \pi}\left[V_{i n}+V_{m} \sin (\theta+\beta)\right] d \theta=0 \\
& \rightarrow V_{m}=\frac{2 \pi}{3 \cos \beta} V_{i n}
\end{aligned}
$$

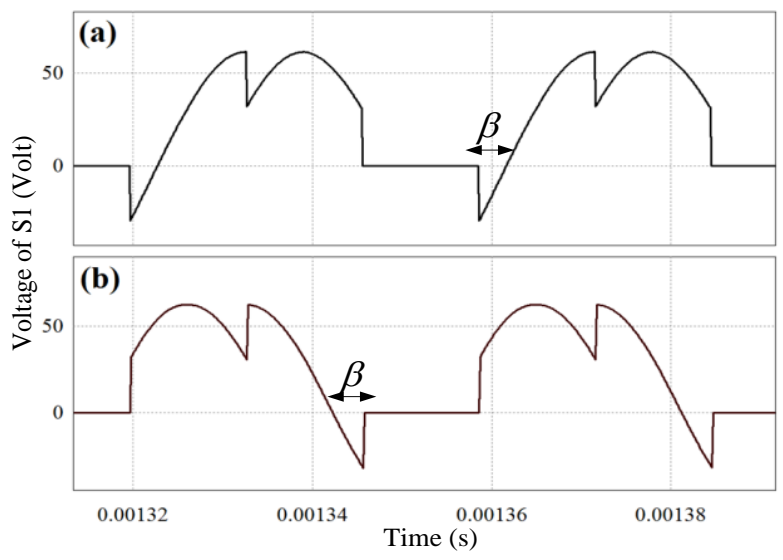

Figure 7

Voltage of $S_{1}$ at the two different conditions: (a) over the resonant frequency; (b) under the resonant frequency

Forthe full-bridge topology, the equation (5) is rewritten as follows:

$\rightarrow V_{m}=\frac{\pi}{3 \cos \beta} V_{i n}$ 


\subsection{Operation with the Tolerances}

Let's consider that each resonant tank has different parameters (different $L_{r}$ and $C_{r}$ ). Hence, the frequency deviation $\Delta f$ caused by the tolerances is derived as follows:

$$
\Delta f=\frac{\partial f_{r}}{\partial L_{r}} \Delta L_{r}+\frac{\partial f_{r}}{\partial C_{r}} \Delta C_{r}=-\frac{1}{4 \pi \sqrt{L_{r} C_{r}}}\left(\frac{\Delta L_{r}}{L_{r}}+\frac{\Delta C_{r}}{C_{r}}\right) \Rightarrow \Delta f=-\frac{f_{r}}{2}\left(\frac{\Delta L_{r}}{L_{r}}+\frac{\Delta C_{r}}{C_{r}}\right)
$$

Figure 8(a) and Figure 8(b) show the phase plot of the three parallel resonant tanks with quality factors of 10 and 2 , respectively. The frequency deviations for the resonant tanks1 to 3 are assumed to be $0 \%,+3 \%$ and $-3 \%$, respectively. The average value of the three resonant frequencies $\left(f_{r 1}, f_{r 2}\right.$ and $\left.f_{r 3}\right)$ is $25 \mathrm{kHz}$.

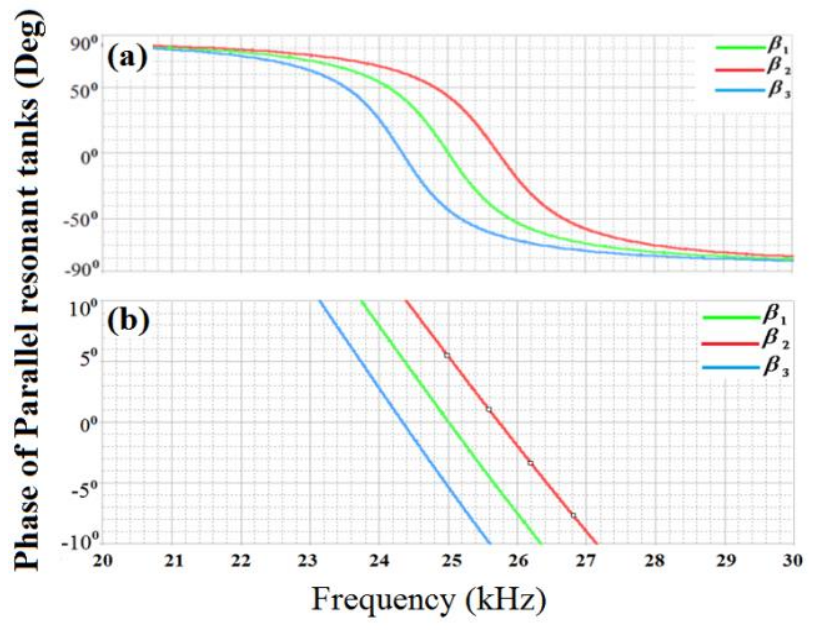

Figure 8

The phase plot of three parallel resonant tanks: (a) quality factor of 10; (b) quality factor of 2

According to equation (2), the phase-phase voltages of the resonant tanks are derived by solving the equations (7) through (9):

$$
\begin{aligned}
& \int_{0}^{2 \pi} V_{L 1} d \theta=\int_{0}^{\frac{2 \pi}{3}} V_{i n} d \theta+\int_{\frac{2 \pi}{3}}^{\frac{4 \pi}{3}}\left[V_{i n}-V_{m 2} \sin \left(\theta-\frac{2 \pi}{3}+\beta_{2}\right)\right] d \theta+\int_{\frac{4 \pi}{3}}^{2 \pi}\left[V_{i n}+V_{m 3} \sin \left(\theta+\beta_{3}\right)\right] d \theta=0 \\
& \int_{0}^{2 \pi} V_{L 2} d \theta=\int_{0}^{\frac{2 \pi}{3}} V_{i n} d \theta+\int_{\frac{2 \pi}{3}}^{\frac{4 \pi}{3}}\left[V_{i n}-V_{m 3} \sin \left(\theta-\frac{2 \pi}{3}+\beta_{3}\right)\right] d \theta+\int_{\frac{4 \pi}{3}}^{2 \pi}\left[V_{i n}+V_{m 1} \sin \left(\theta+\beta_{1}\right)\right] d \theta=0 \\
& \int_{0}^{2 \pi} V_{L 3} d \theta=\int_{0}^{\frac{2 \pi}{3}} V_{i n} d \theta+\int_{\frac{2 \pi}{3}}^{\frac{4 \pi}{3}}\left[V_{i n}-V_{m 1} \sin \left(\theta-\frac{2 \pi}{3}+\beta_{1}\right)\right] d \theta+\int_{\frac{4 \pi}{3}}^{2 \pi}\left[V_{i n}+V_{m 2} \sin \left(\theta+\beta_{2}\right)\right] d \theta=0
\end{aligned}
$$




$$
\rightarrow\left\{\begin{array}{l}
V_{m 2} \cos \left(\beta_{2}-\frac{\pi}{6}\right)+V_{m 3} \cos \left(\beta_{3}+\frac{\pi}{6}\right)=\frac{2 \pi}{\sqrt{3}} V_{i n} \\
V_{m 3} \cos \left(\beta_{3}-\frac{\pi}{6}\right)+V_{m 1} \cos \left(\beta_{1}+\frac{\pi}{6}\right)=\frac{2 \pi}{\sqrt{3}} V_{i n} \\
V_{m 1} \cos \left(\beta_{1}-\frac{\pi}{6}\right)+V_{m 2} \cos \left(\beta_{2}+\frac{\pi}{6}\right)=\frac{2 \pi}{\sqrt{3}} V_{i n}
\end{array}\right.
$$

The $V_{L 1}, V_{L 2}$ and $V_{L 3}$ are voltage of the DC-link inductors $\left(L_{1}, L_{2}\right.$ and $\left.L_{3}\right)$. According to Figure 2, the $V_{m 1}, V_{m 2}$ and $V_{m 3}$ are equal to the following values:

$$
\left\{\begin{array}{l}
V_{m 1}=V_{L r 1}-V_{L r 2} \\
V_{m 2}=V_{L r 2}-V_{L r 3} \\
V_{m 3}=V_{L r 3}-V_{L r 1}
\end{array}\right.
$$

$V_{L r 1}, V_{L r 2}$ and $V_{L r 3}$ are the voltage ofthe resonant inductors shown in Figure 2. By solving the equation set (10), the phase-phase voltages are derived as a function of $\beta_{1}, \beta_{2}, \beta_{3}$ and $V_{i n}$. For the full-bridge inverter, the equation set (10) can be rewritten by employing the inductor volt-second balance principle on $L_{d}$ and considering the following complex equation:

$$
V_{m 1} \exp \left(j \beta_{1}\right)+V_{m 2} \exp \left(j \beta_{2}-j \frac{2 \pi}{3}\right)+V_{m 3} \exp \left(j \beta_{3}+j \frac{2 \pi}{3}\right)=0, j=\sqrt{-1}
$$

Figure 9 shows the phase-phase voltages of the full-bridge inverter with frequency deviations. In this figure, the resonant frequencies, $f_{r 1}, f_{r 2}$ and $f_{r 3}$ are $25 \mathrm{kHz}, 26.5$ $\mathrm{kHz}$ and $25 \mathrm{kHz}$, respectively ( $+6 \%$ deviations for $f_{r 2}$ ). The quality factor of each resonant tank is approximately 20 and the DC-link voltage, $V_{i n}$, is $50 \mathrm{~V}$. In Figure 9(a), a conventional PLL tracks the resonant frequency of $f_{r 2}$ at steady state condition, hence the switching frequency is $26.5 \mathrm{kHz}$.

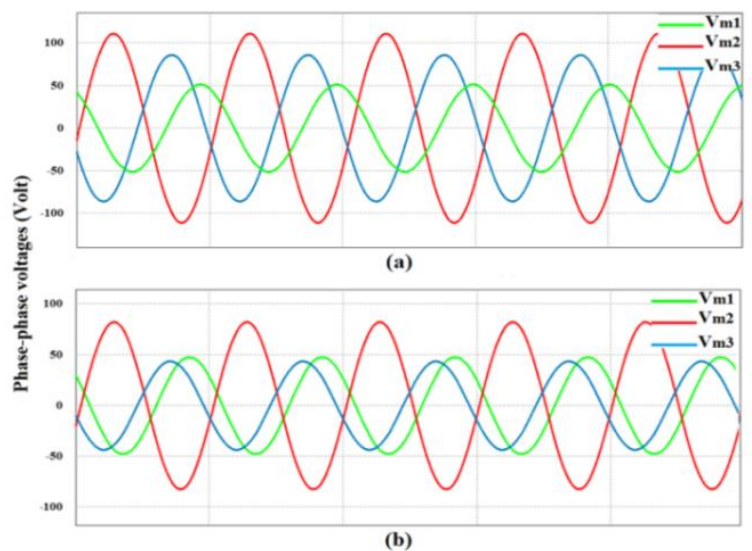

Figure 9

Phase-phase voltage of full bridge parallel resonant inverter: (a) the switching frequency is $26.5 \mathrm{kHz}$;

(b) the switching frequency is $25.5 \mathrm{kHz}$ 
Figure 9(b) shows the phase-phase voltages of the full-bridge inverter with the same tolerances. In Figure 9(b), the PLL tracks the average value of the three resonant frequencies, $25.5 \mathrm{kHz}$, by using the proposed PLL.

Comparing Figure 9(a) and Figure 9(b), it can be concluded that the voltage stress of the inverter is reduced by $20 \%$ when the switching frequency is equal to the average value of the resonant frequencies, $25.5 \mathrm{kHz}$. Hence, for high quality factor (or light-load) conditions $(Q>5)$, the voltage stress of the inverter is significant when the resonant inverter tuning is based on single-phase tuning or conventional PD's.

It can be proven that the minimum value of the voltage stresses occurs when the equation (13) is satisfied. The equation (13) shows a condition that the switching frequency is set to the average value of the resonant frequencies. In the next section, this condition and the performance of the proposed PLL are described in more details.

$$
\min \left\{\max \left(V_{m 1}, V_{m 2}, V_{m 3}\right)\right\} \Leftrightarrow \beta_{1}+\beta_{2}+\beta_{3}=0
$$

Without loss of generality, consider that the switching frequency of the inverter is tuned by using a conventional PLL that tracks the resonant frequency of $f_{r l}$. Regarding equations (10) through (13), there is extra voltage stress. The extra stress is maximum for nonsymmetrical tolerances (e.g. $\pm 0 \%, \pm 0 \%$ and $\pm 6 \%$ ), and is minimum for symmetrical tolerances (e.g. $+3 \%,-3 \%$ and $\pm 0 \%$ ). The voltage stress increases the current ripples of the DC-link inductor and decreases the net efficiency. The extra voltage stress is suppressed by using the proposed method, which satisfies the equation (13).

Figure 10 shows the stress reduction (in percentage) of the proposed technique for different quality factors and for nonsymmetrical and symmetrical tolerances. Figure 11 shows the voltage of the DC-link inductorwhen the full-bridge inverter is tuned by the conventional and proposed methods at quality factor of about 10 and nonsymmetrical tolerances. Regarding Figure 10 and Figure 11, the DC-link ripples are more affected by the voltage stress for a specific quality factor and frequency deviation.

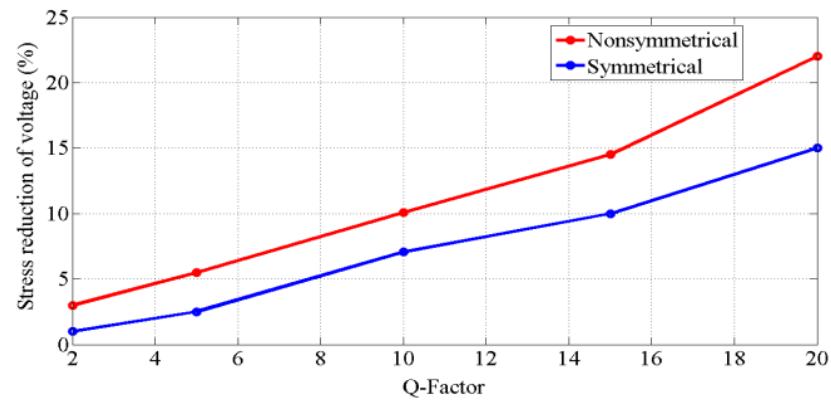

Figure 10

Percentage of stress reduction for the symmetrical and nonsymmetrical tolerances 


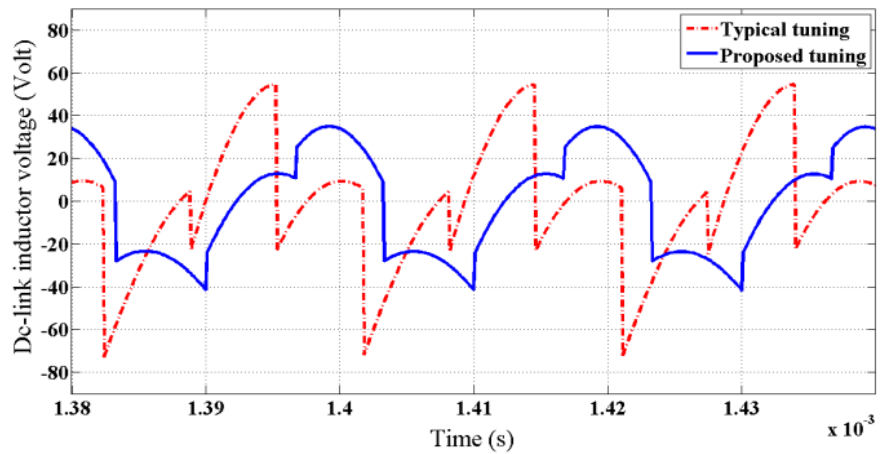

Figure 11

Voltage of DC-link inductor for the proposed and conventional techniques at quality factor of 10 for the full-bridge topology

Forlow quality factors, the system approximately works like a balanced threephase system because the phase deviations are negligible, see Figure 8(b) and equation set (10). However, the switching frequency should be equal to the average value of the resonant frequencies to minimize the switching losses, negative sequences and DC-link current ripples.

\section{The Proposed Resonant Inverter Tuning}

PLL circuit consists of a Voltage Controlled Oscillator (VCO), Phase Detector (PD) and a Loop Filter (LF). There are three important parameters for a PLL circuit: VCO's gain $K_{V}$, center frequency $f_{c}$ and LF parameters [25]. In this paper, the LFs are $R C$ filterswith time constant of $\tau$.

A three-phase PD is proposed which only uses the voltage of the switches and has no current sensor in the tuning loop. The PD directly connects to LF units to build a Multiplier PD mode [23-25]. To construct the three-phase PD, voltages of $S_{1}, S_{2}$, and $\mathrm{S}_{3}\left(V_{S 1}, V_{S 2}\right.$ and $\left.V_{S 3}\right)$ are passed through comparators and then connected to a logic circuit to produce the phase error signals. According to comparators, the voltage of the switches are saturated in both positive and negative values to produce $V_{S 1+}, V_{S 1-}, V_{S 2+}, V_{S 2-}, V_{S 3+}$ and $V_{S 3 \text {. }}$ Figure 12(a) shows waveforms of $V_{S 1}$, $V_{S I}$ and $V_{S I+}$ when the inverter works at over the resonant frequency. Figure 12(b) and 12(c) show the voltage of the switches at over and under the resonant frequency for thehalf-bridge inverter and input voltage of $25 \mathrm{~V}$.

Regarding Figure 12, the phase differences $\left(\beta_{1}, \beta_{2}\right.$ and $\left.\beta_{3}\right)$ aresimplyproduced by using AND gates. For instance, to produce the $\beta_{l}$ when the inverter works at over the resonant frequency ( or $\beta_{I}<0$ ), $V_{S I}$ and $V_{S 3+}$ are the inputs of the AND gate, see Figure 12(b). 


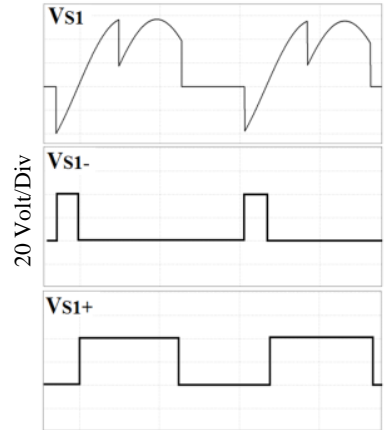

(a)

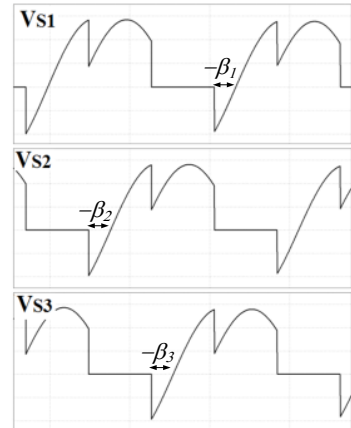

(b)

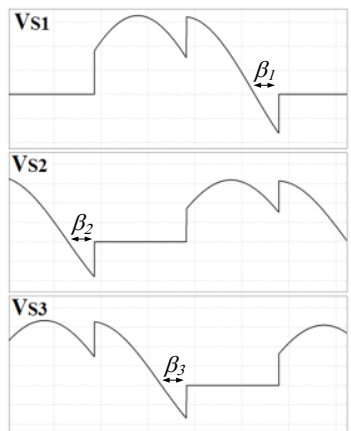

(c)

Figure 12

Switches' voltages: (a) voltage of $S_{1}$ and its positive and negative duration; (b) voltage of switches at over the resonant frequency; (c) voltage of switches at under the resonant frequency

Equation (14) shows the relationships between $\beta_{1}$ and voltage of the switches. The output of the AND gates are passed through Loop Filters (LF) to remove high frequency components.

$\left\{\begin{array}{lll}x_{1}=V_{S 1-} \& V_{S 3+}=\beta_{1} & , & \beta_{1}<0 \\ x_{1}=V_{S 1-} \& V_{S 3+}=0 & , & \beta_{1} \geq 0 \\ x_{2}=V_{S 1-} \& V_{S 2+}=0 & , & \beta_{1} \leq 0 \\ x_{2}=V_{S 1-} \& V_{S 2+}=\beta_{1} & , & \beta_{1}>0\end{array} \rightarrow \beta_{1}=x_{2}-x_{1}\right.$

To produce the three-phase PD signals, there are six AND signals, $x_{1} \ldots x_{6}$, which are implemented to produce the phase differences as follows:

$$
\begin{cases}x_{1}=V_{S 1-} \& V_{S 3+}, x_{2}=V_{S 1-} \& V_{S 2+} & \text { for } \beta_{1} \\ x_{3}=V_{S 2-} \& V_{S 1+}, x_{4}=V_{S 2-} \& V_{S 3+} & \text { for } \beta_{2} \\ x_{5}=V_{S 3-} \& V_{S 2+}, x_{6}=V_{S 3-} \& V_{S 1+} & \text { for } \beta_{3}\end{cases}
$$

According to (15) and Figure 12, the output of phase detector, $\alpha$ is derived as follows:

$$
\alpha=\left(\beta_{1}+\beta_{2}+\beta_{3}\right)=\left[\left(x_{2}+x_{4}+x_{6}\right)-\left(x_{1}+x_{3}+x_{5}\right)\right]
$$

Figure 13 shows the proposed PD circuit with VCO and LF units. To analyze the performance of the PLL, the phase plot of thetank circuits must be linearized at their resonant frequencies as follows [21-23].

$$
K_{\beta i}=-\left.\frac{\partial \beta_{i}(j 2 \pi f)}{\partial f}\right|_{f=f_{i i}}
$$

The $K_{\beta 1}, K_{\beta 2}$ and $K_{\beta 3}$ are the slope of the phase curves near their resonant frequencies in $\mathrm{rad} / \mathrm{Hz}$. According to Figure 8 and considering that the deviations are below $3 \%$, theslopes are similar for $\left|\beta_{i}\right|<30^{\circ}$. 


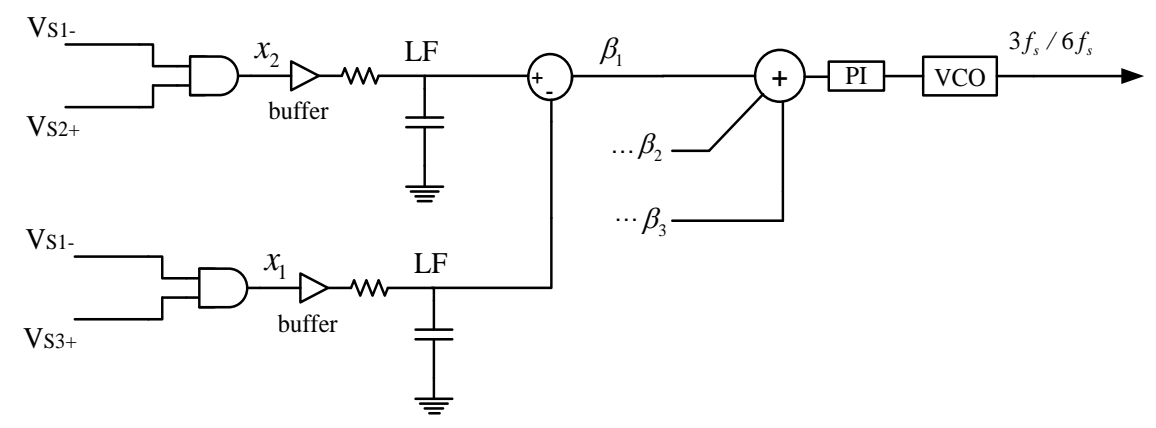

Figure 13

The proposed three-phase PD with VCO and LF units

$\rightarrow K_{\beta 1}=K_{\beta 2}=K_{\beta 3}=K_{\beta}$

Therefore, the phase differencescan be derived by equation (18) as follows:

$\beta_{1}=K_{\beta}\left(f_{r 1}-f_{s}\right)$

$\beta_{2}=K_{\beta}\left(f_{r 2}-f_{s}\right)$

$\beta_{3}=K_{\beta}\left(f_{r 3}-f_{s}\right)$

The $f_{s}$ is the switching frequency of the inverter. Hence, the equation (16) is rewritten as follows:

$\alpha=K_{\beta}\left(f_{r 1}+f_{r 2}+f_{r 3}\right)-3 K_{\beta} f_{s}$

At steady state condition, $\alpha$ isapproximately zero and hence, the switching frequency is derived as follows:

$\alpha \rightarrow 0 \Leftrightarrow f_{s}=\frac{\left(f_{r 1}+f_{r 2}+f_{r 3}\right)}{3}$

By designing a proper PI controller, $\alpha$ is close to zero at steady state condition. According to (20), the proposed PLL tracks the average value of the resonant frequencies. As seen from Figure 14, the output of the PD is passed through the PI controller. The output of the controller is connected to the VCO unit. According to Figure 12 and equation (16), it is worth noting that the high frequency component of the proposed PD is six times the switching frequency (or three times the conventional PD's) [21-25]. Therefore, the proposed method has fast dynamics and the tuning process occurs in less cycles.

Due to three-pulse and six-pulse operation of the half-bridge and full-bridge inverters, the center frequency of the PLL must be close to three times and six times of the resonant frequency. Figure 14 shows the switching sequences for $120^{\circ}$ conduction mode for full-bridge and half-bridge topologies. Finally, the output of the VCO is connected to a sequential circuit to produce the proper switching sequences. 


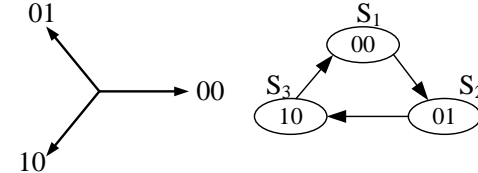

(a)

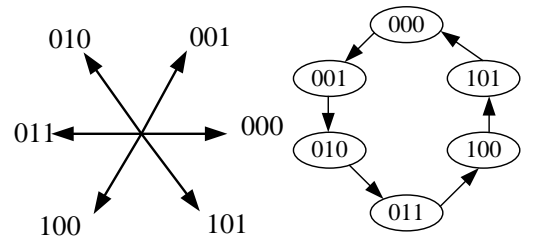

(b)

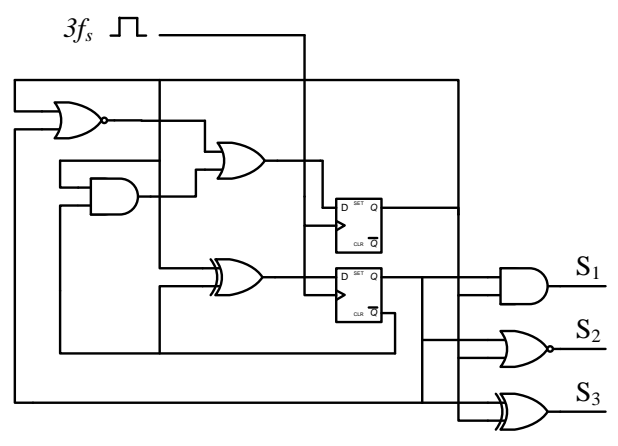

(c)

Figure 14

(a) The three-step performance of sequential circuitfor half-bridge inverter; (b) six-step performance of sequential circuitfor full-bridge inverter; (c) the sequential circuit used for half-bridge inverter

Figure 14(c) shows the proposed sequential circuit for the half-bridge topology. To show the PLL dynamics, simulation results are carried out by PSIM simulator for the half-bridge topology. The parameters of the inverter and the PLL are listed in Table 1. Figure 15(a) shows the voltage of $S_{1}$ and the PLL dynamics at start-up. Figure 15(b) shows output signal of the phase detector controller (or input signal of the VCO unit) at start-up. In these figures, the center frequency $f_{c}$ of the PLL is $65 \mathrm{kHz}$, which is approximately three times the resonant frequency. According to the resonant frequency, the final frequency of the VCO unit is close to $66 \mathrm{kHz}$.

In this simulation, the tolerances are less than $3 \%$ and the average value of the resonant frequencies is about $22 \mathrm{kHz}$. The parameters of the PI controller are set to achieve better dynamics. This simulation is done without power regulator. However, by using a power regulator, the voltage stresses of the switches are significantly reduced at start-up,as in [24]. As seen from Figure 15, the output voltage of the controller has three steps for each switching period, which is three times faster thanconventional PD's [21-25].

Table 1

Simulation parameters

\begin{tabular}{|c|c|c|c|c|c|}
\hline \multicolumn{2}{|c|}{$\begin{array}{c}\text { Resonant tank } \\
\text { parameters }\end{array}$} & \multicolumn{2}{c|}{ Inverter Parameters } & \multicolumn{2}{c|}{ PLL specifications } \\
\hline$C_{r}$ & $330 \mathrm{nF}$ & $L_{I, 2,3}$ & $600 \mu \mathrm{H}$ & $f_{c}$ & $65 \mathrm{kHz}$ \\
\hline$Q$ & $\approx 5$ & $V_{i n}$ & $50 \mathrm{~V}$ & $\begin{array}{c}P \\
I\end{array}$ & $K_{I}=5.5 \times 10^{4}, K_{P}=20$ \\
\hline$L_{r}$ & $150 \mu \mathrm{H}$ & - & - & $\tau$ & $330 \mu \mathrm{Sec}$ \\
\hline$f_{r}$ & $\approx 22 \mathrm{kHz}$ & - & - & $\begin{array}{c}K \\
V\end{array}$ & $1000(\mathrm{~Hz} / \mathrm{Volt})$ \\
\hline
\end{tabular}




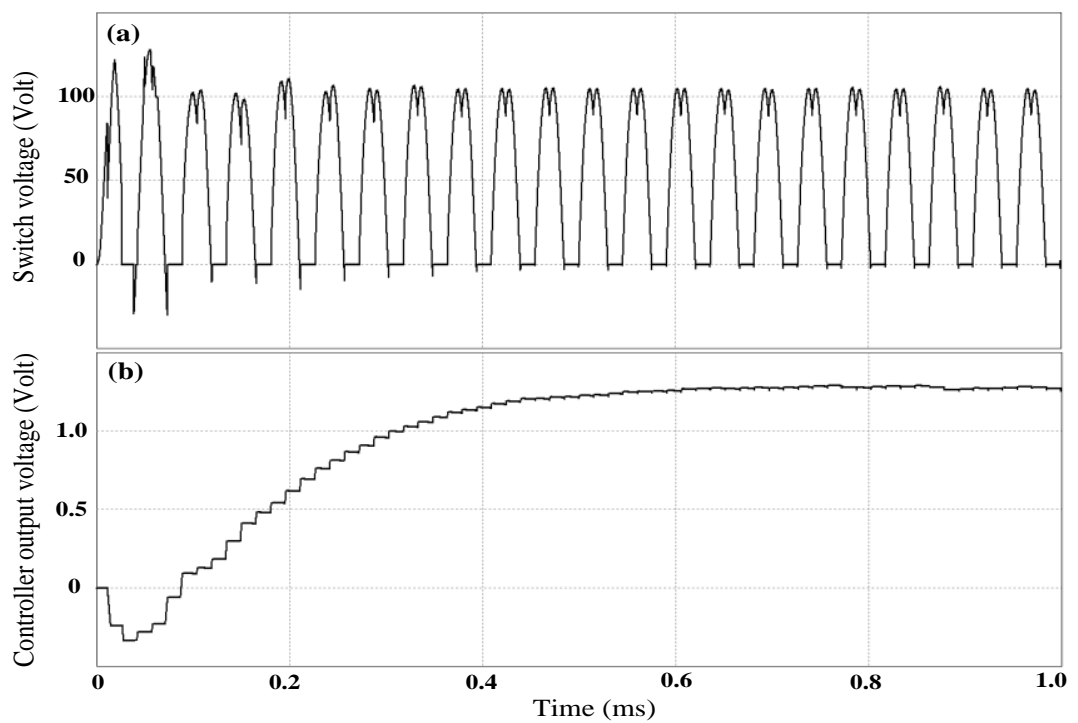

Figure 15

(a) Voltage of $S_{1}$ at start-up condition; (b) output signal of the PI controller at start-up condition

\section{Experimental Results}

A half-bridge inverterwas built and the performance of the inverter with the new PLL was investigated with operating frequency of $22 \mathrm{kHz}$. As mentioned, the structure of the PDis similar for the full-bridge and half-bridge inverters and the half-bridge topology is implementedfor simplicity. The parameters of the inverter and the PLL are listed in Table 2. In this prototype, the quality factor of the resonant tanks is investigated for 20 and 3. The quality factor of 20 is considered for the no-load condition. The center frequency of VCO is about $65 \mathrm{kHz}$ for operating frequency of about $22 \mathrm{kHz}$.

Tolerance of theresonant inductor, $L_{r}$, is less than $1 \%$ and the resonant capacitors are metalized polypropylene film capacitor with maximum tolerance of $5 \%$. Therefore, according to (6), the maximum frequency deviationis less than $3 \%$ for each resonant tank. In this prototype, the equivalent load resistances are in series with resonant inductors for mentioned quality factors.

Figure 16(a) shows the performance of the new PLL at start-up condition. In this figure, the PLL's center frequency is $65 \mathrm{kHz}$, which is approximately three times the average value of the resonant frequencies. The steady state switching frequency (or averaged value of three resonant frequencies) is about $22 \mathrm{kHz}$ at quality factor of 20 . 


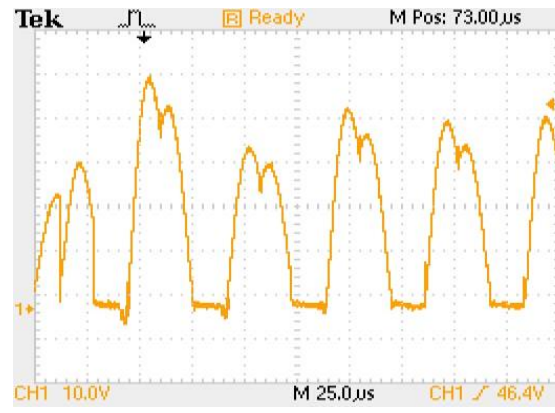

(a)

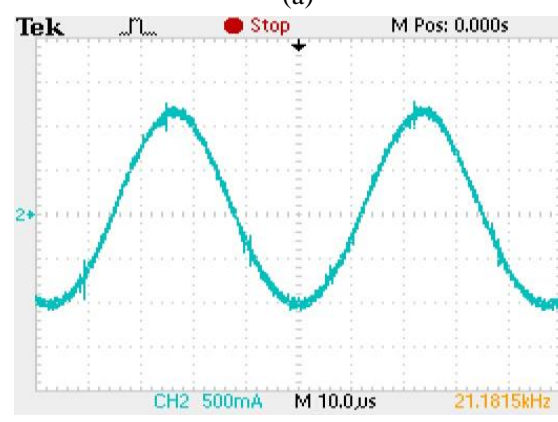

(c)

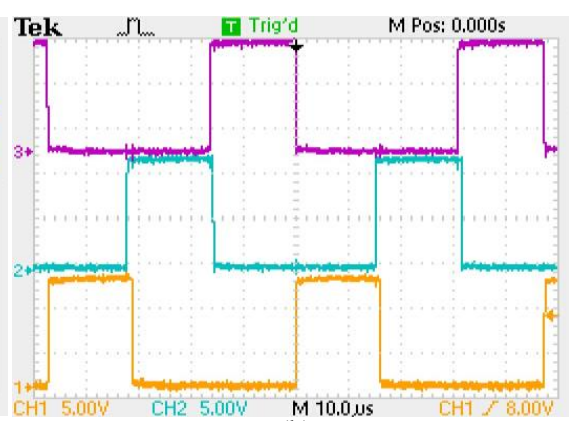

(b)

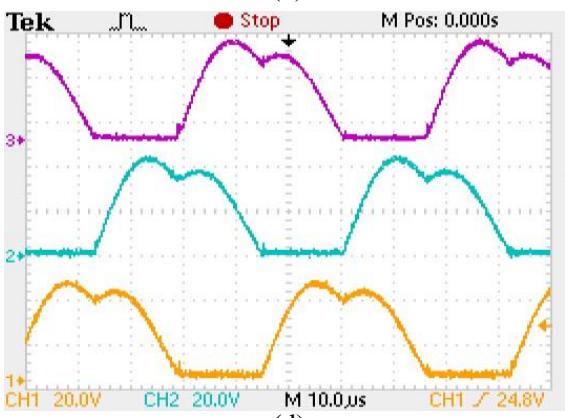

(d)

Figure 16

(a) Voltage of $S_{1}$ at start-up condition by using the proposed tuning loop and input voltage of $20 \mathrm{~V}$ (10 volt/div); (b) gate to source voltage of the switches, (5 volt/div); (c) resonant tank current at quality factor of about 3, (500mA/div); (d) voltage of the switches at steady state condition and input voltage of $20 \mathrm{~V}$ and quality factor of about 3, (20 volt/div)

Table 2

Inverter and PLL parameters

\begin{tabular}{|c|c|c|c|c|c|}
\hline \multicolumn{2}{|c|}{ Load parameters } & \multicolumn{2}{c|}{ Inverter Parameters } & \multicolumn{2}{c|}{ PLL specifications } \\
\hline$C_{r}$ & $\approx 330 \mathrm{nF}$ & $L_{l, 2,3}$ & $600 \mu \mathrm{H}$ & $f_{\text {center }}$ & $\approx 65 \mathrm{kHz}$ \\
\hline$Q$ & $\approx 20$ and 3 & Series diodes & BY399 & PI & $K_{I} \approx 6 \times 10^{4}, K_{P} \approx 15$ \\
\hline$L_{r}$ & $\approx 150 \mu \mathrm{H}$ & Switches & IRFP540 & $\tau$ & $1000 \mu \mathrm{Sec}$ \\
\hline$f_{r}$ & $\approx 22 \mathrm{kHz}$ & Gate drivers & ICL7667 & $K_{V}$ & $1000(\mathrm{~Hz} / \mathrm{Volt})$ \\
\hline
\end{tabular}

The PI controller of the PLL circuit is designed to achieve minimum phase error at steady state condition while the transient response is suitable. The optimum parameters of the PI controller are listed in Table 2. Figure 16(b) and (d) show the gating signals and the voltage of the switches at quality factor of about 3 with $3 \%$ deviation. Figure 16(c) shows resonant tank current connected to $S_{1}$ at the quality factor of 3 and output power of about $50 \mathrm{~W}$. Figure 17 shows the laboratory prototype of the current source parallel resonant half-bridge inverterwith the resonant inductors and capacitors. 


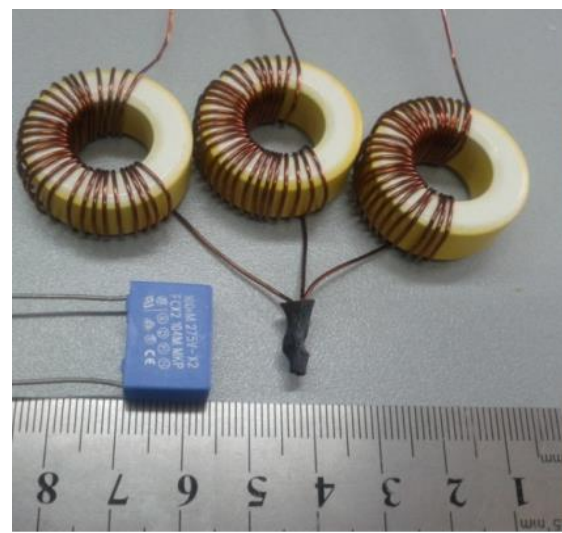

(a)

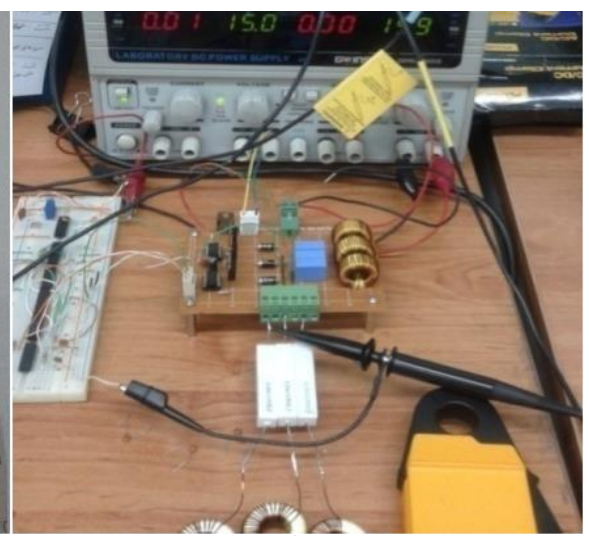

(b)

Figure 17

(a) The three resonant inductors and the resonant capacitor; (b) laboratory prototype of the current source parallel resonant half-bridge inverter

\section{Conclusion}

In this paper, a new PLL circuit is proposed for three-phase current source parallel resonant inverters. The new PLL tracks the average value of three resonant frequencies according to the new phase detector performance. This helps to achieve less voltage stresses on the switches and lower distortions in DC-link current. The PLL is investigated in multiplier phase and frequency mode to achieve fast dynamics at transients. The new tuning circuit uses only the voltage of the switches to detect the phase error and there is no feedback from the load currents. Therefore, the circuit is simple, more reliable and cost effective. The new PLL can be used for both full-bridge and half-bridge topologies while the sequential circuit difference must be taken in consideration.

\section{References}

[1] H. R. E. Larico and I. Barbi: Three-Phase Weinberg Isolated DC-DC Converter: Analysis, Design, and Experimentation, IEEE Transaction on Industrial Electronics, Vol. 59, No. 2, 2012, pp. 888-896

[2] G. A. Covic, J. T. Boys, M. L. G. Kissin and H. G. Lu: A Three-Phase Inductive Power Transfer System for Roadway-Powered Vehicles, IEEE Transaction on Industrial Electronics, Vol. 54, No. 6, 2007, pp. 3370-3378

[3] S. V. G. Oliveira and I. Barbi: A Three-Phase Step-Up DC-DC Converter With a Three-Phase High-Frequency Transformer for DC Renewable Power Source Applications, IEEE Transaction on Industrial Electronics, Vol. 58, No. 8, 2011, pp. 3567-3580 
[4] P. Alotto, A. Spagnolo and B. Paya: Particle Swarm Optimization of a Multi-Coil Transverse Flux Induction Heating System, IEEE Transaction on Magnetics, Vol. 47, No. 5, 2011

[5] J. Egalon, S. Caux, P. Maussion, M. Souley and O. Pateau: Multiphase System for Metal Disc Induction Heating: Modeling and RMS Current Control, IEEE Transaction on Industrial Application, Vol. 48, No. 5, pp. 1692-1699, 2012

[6] M. Daigavane, H. Suryawanshi and J. Khan: A Novel Three Phase SeriesParallel Resonant Converter Fed DC-Drive System, Journal of Power Electronics, Vol. 7, No. 3, 2007, pp. 22-232

[7] H. Matsumoto, Y. Neba, K. Ishizaka and R. Itoh: Model for a Three-Phase Contactless Power Transfer System, IEEE, Transaction on Power Electronics, Vol. 26, No. 9, 2011, pp. 2676-2687

[8] R. L. Andersen and I. Barbi: A Three-Phase Current-Fed Push-Pull DCDC Converter, Transaction on Power Electronics, Vol. 24, No. 2, 2011, pp. 358-368

[9] L. Pang, Y. Wang and T. Chen: New development of traveling wave induction heating, IEEE. Transaction on Applied Superconductivity, Vol. 20, No. 3, 2010, pp. 1013-1016

[10] Y. Hwang, B. Hwang, H. Lin and J. Chen: PLL-based Contactless Energy Transfer Analog FSK Demodulator using High Efficiency Rectifier, IEEE Transaction on Industrial Electronics, Vol. 60, No. 1, 2013, pp. 280-290

[11] R. L. Lin and C. H. Wen: Three-Phase Electronic Ballast with CurrentEqualization Function, Journal of Display Technology, Vol. 2, No. 4, pp. 378-385, 2006

[12] Z. Wang and H. Li: A Soft Switching Three-Phase Current-fed Bidirectional DC-DC Converter with High Efficiency over a Wide Input Voltage Range, IEEE Transaction on Power Electronics, Vol. 27, No. 2, 2012, pp. 669-684

[13] S. Lee, J. Park and S. Choi: A Three-Phase Current-Fed Push-Pull DC-DC Converter With Active Clamp for Fuel Cell Applications, IEEE Transaction on Power Electronics, Vol. 26, No. 8, 2011, pp. 2266-2277

[14] S. K. Changchien, T. J. Liang, J. F. Chen and L. S. Yang: Novel High StepUp DC-DC Converter for Fuel Cell Energy Conversion System, IEEE Transaction on Industrial Electronics, Vol. 57, No. 6, 2010, pp. 2007-2017

[15] J. M. Kwon, E. H. Kim, B. H. Kwon and K. H. Nam: High-Efficiency Fuel Cell Power Conditioning System With Input Current Ripple Reduction, IEEE Transaction on Industrial Electronics, Vol. 56, No. 3, 2009, pp. 826834 
[16] B. Yuan, X. Yang, X. Zeng, J. Duan, J. Zhai and L. Donghao: Analysis and Design of a High Step-up Current-Fed Multiresonant DC-DC Converter With Low Circulating Energy and Zero-Current Switching for All Active Switches, IEEE Transaction on Industrial Electronics, Vol. 59, No. 2, 2012, pp. 964-978

[17] R. Casanueva, C. Brañas, F. J. Azcondo and F. J. Díaz: Teaching Resonant Converters: Properties and Applications for Variable Loads, IEEE Transaction on Industrial Electronics, Vol. 57, No. 10, 2010, pp. 3355-3363

[18] S. Jalbrzykowski and T. Citko: Current-Fed Resonant Full-Bridge Boost DC/AC/DC Converter, IEEE Transaction on Industrial Electronics, Vol. 55, No. 3, 2008, pp. 1198-1205

[19] A. L. Shenkman, B. Axelord and V. Chudnovsky: A New Simplified Model of the Dynamics of the Current-Fed Parallel Resonant Inverter, IEEE Transaction on Industrial Electronics, Vol. 47, No. 2, 2000, pp. 282-286

[20] M. K. Kazimierczuk, A. Abdulkarim: Current-Source Parallel-Resonant DC/DC Converter, IEEE Transaction on Industrial Electronics, Vol. 42, No. 2, 1995, pp. 199-208

[21] N. Margaris and V. Petridis: Voltage Pump Phase-locked Loops, IEEE Transaction on Industrial Electronics, Vol. 32, No. 1, 1985, pp. 41-49

[22] A. Namadmalan and J. S. Moghani: Tunable Self-Oscillating Switching Technique for Current Source Induction Heating Systems, IEEE, Transaction on Industrial Electronics, Vol. 61, No. 1, 2014, pp. 2556-2563

[23] H. Karaca and S. Kılınç: Nonlinear Modeling and Analysis of Resonant Inverter Tuning Loops with Voltage-Pump Phase-Frequency Detector, IEEE, Transaction on Power Electronics, Vol. 20, No. 5, 2005, pp. 11001108

[24] A. Namadmalan, J. S. Moghani and J. Milimonfared: A Current-fed Parallel Resonant Push-Pull Inverter with a New Cascaded Coil Flux Control for Induction Heating Applications, Journal of Power Electronics, Vol. 11, No. 5, 2011

[25] G. C. Hsieh and J. C. Hung: Phase-Locked Loop Techniques-A Survey, IEEE, Transaction on Industrial Electronics, Vol. 43, No. 6, 1996 